\title{
FERMENTAÇÃO ANAERÓBICA DO COLOSTRO EQUINO
}

\author{
BRASIL, Carolina Litchina ${ }^{1}$; \\ VALENTE, Julia de Souza Silveira ${ }^{2}$; \\ BRAGA, Caroline Quintana ${ }^{3}$; \\ PEREIRA, Camila Corrêa ${ }^{4}$; \\ VIANNA, Ana Munhoz ${ }^{5}$; \\ LEITE, Fábio Pereira Leivas ${ }^{6}$; \\ NOGUEIRA, Carlos Eduardo Wayne ${ }^{7}$; \\ PEREIRA, Daniela Isabel Brayer ${ }^{8}$.
}

Recebido: 22/01/2019

Aceito: 01/04/2019

${ }^{1}$ Médica Veterinária, Mestra, Programa de Pós-Graduação em Parasitologia/UFPEL; ${ }^{2}$ Bióloga, Mestra, Programa de Pós-Graduação em Parasitologia/UFPEL; ${ }^{3}$ Bióloga, Programa de Pós-Graduação em Parasitologia/UFPEL; ${ }^{4}$ Química Industrial, Mestra, Doutora, Programa de Pós-Graduação em Química/UFPEL;

${ }^{5}$ Farmacêutica, Mestra, Doutora, Programa de Pós-Graduação em Veterinária/UFPEL; ${ }^{6}$ Professor Associado, CDTec/UFPEL; ${ }^{7}$ Professor Associado, Faculdade de Veterinária/UFPEL; ${ }^{8}$ Professora Associada, Instituto de Biologia/UFPEL.

\section{RESUMO}

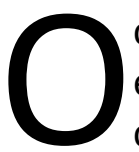

colostro equino fornece imunoglobulinas, nutrientes e fatores de crescimento essenciais à imunidade e sobrevivência do potro neonato. No entanto, em inúmeros casos, a ingestão do colostro pelo neonato não ocorre de forma natural, sendo necessário o aleitamento artificial. Métodos de preservação do colostro têm gerado resultados controversos. O objetivo deste estudo foi testar a técnica de fermentação anaeróbica do colostro equino, a fim de preservar a qualidade do produto e avaliar, in vitro, a manutenção dos constituintes colostrais. Foram verificadas as propriedades microbiológicas, físicas e a concentração de analitos: cálcio $(\mathrm{Ca})$, potássio $(\mathrm{K})$, magnésio $(\mathrm{Mg})$ e sódio $(\mathrm{Na})$ do colostro in natura e em distintos períodos de fermentação anaeróbica. A avaliação do pH no decorrer da fermentação demonstrou redução condizente com processo fermentativo. Nos distintos períodos de fermentação, foi observada manutenção das concentrações dos analitos e dos níveis de imunoglobulinas. Os resultados deste estudo evidenciam que a silagem do colostro equino mantém as propriedades avaliadas in vitro.

Palavras-chave: Silagem. Imunidade. Imunoglobulinas. 


\section{INTRODUÇÃO}

O colostro equino caracteriza-se como uma secreção láctea do úbere gravídico, que inicia sua liberação lentamente nas últimas semanas de gestação e continua por 24 a 48 horas após o parto. Sua principal função é a transferência passiva de imunoglobulinas maternas para o potro neonato, período de maior suscetibilidade às infecções neonatais, e perdura até o momento em que os animais sejam responsivos aos desafios ambientais (GARDNER et al., 2007).

A espécie equina é dependente da transferência passiva de imunoglobulinas maternas, nutrientes, hormônios e fatores de crescimento presentes no colostro, devendo ser ingerido imediatamente após o nascimento. Essa dependência ocorre, principalmente, pela necessidade de aquisição de imunidade, pois devido ao tipo de placentação na égua (epitélio-corial difusa) não há transferência de moléculas maiores de 150 kDa via transplacentária durante a fase intrauterina do potro. Por isso, os potros nascem sem imunidade humoral, sendo considerados hipoglobulinêmicos ou agamaglobulinêmicos ao nascimento (LEBLANC et al., 1986; SIMON et al., 2012).

Em muitos casos, a oferta do colostro ao neonato não é possível em função da indisponibilidade materna ou por problemas do potro ao nascimento. Nessas situações, a solução mais indicada é o aleitamento artificial, que é uma prática bastante antiga e conhecida entre os médicos veterinários clínicos (GIGUERE; POLKES, 2005).

O colostro pode ser fornecido na sua forma natural, fresco ou conservado. Na equinocultura, a forma de conservação do colostro mais utilizada é o congelamento à temperatura de -20 ${ }^{\circ} \mathrm{C}$, o qual preserva esse produto por até 12 meses. No entanto, muitas de suas propriedades imunológicas podem ficar comprometidas por fatores como: energia elétrica inconstante, causando descongelamentos indesejáveis, temperatura errônea de descongelamento e material para conservação sem higiene adequada (GIGUERE; POLKES, 2005). Com isso, estudos avaliando alternativas de preservação do colostro equino são necessários e relevantes.

Saalfeld (2008) implementou e avaliou a fermentação anaeróbica de colostro bovino como forma de aproveitamento do excesso de colostro produzido nas propriedades rurais. 0 
método consistiu na fermentação anaeróbica do colostro. A silagem do colostro bovino não só mantém as características físico-químicas do colostro in natura, como também a presença de Lactobacillus spp. e outros constituintes, incluindo as proteínas (ANDRADE et al., 2012). Adicionalmente, Saalfeld et al. (2013) comprovaram que os níveis de imunoglobulinas na silagem de colostro bovino são mantidos, sendo transferidas eficientemente para o recémnascido. Pereira et al. (2016), através da determinação de cálcio (Ca), ferro (Fe), potássio (K), magnésio $(\mathrm{Mg})$, sódio $(\mathrm{Na})$ e zinco $(\mathrm{Zn})$, em amostras de silagem de colostro bovino, comprovaram que ocorre uma manutenção da concentração dos analitos no colostro, com níveis superiores aos encontrados no leite.

O objetivo deste estudo foi testar a técnica de fermentação anaeróbica do colostro equino, a fim de preservar a qualidade do produto e avaliar, in vitro, a manutenção dos constituintes colostrais.

\section{MATERIAL E MÉTODOS}

\section{Animais}

Foram utilizadas 35 éguas prenhes, sendo nove éguas sem raça definida com idade entre sete e vinte e um anos, com média de idade de 16 anos, pertencentes ao Centro de Ensino e Experimentação em Equinocultura da Palma (CEEP) da Universidade Federal de Pelotas, Rio Grande do Sul. As demais 26 éguas, da raça Crioula, com idade entre seis e vinte anos, com média de idade de 16 anos, eram provenientes de um criatório situado no município do Capão do Leão, Rio Grande do Sul. Todas as éguas tiveram gestações saudáveis, com condições nutricionais e higiênico-sanitárias similares, sendo multíparas e com média de tempo de gestação de 332 dias. Em todas as fêmeas foi realizado o acompanhamento gestacional, monitoramento e avaliação do parto.

O projeto foi aprovado pela Comissão de Ética em Experimentação Animal da Universidade Federal de Pelotas sob o no 1890-2016. 


\section{Coleta do colostro e preparo da silagem}

As coletas de colostro foram realizadas direto da glândula mamária no prazo de até seis horas após o parto. Previamente, foi realizada a antissepsia do úbere, sendo desprezados os primeiros jatos de colostro. Para cada égua foi coletado um volume de $300 \mathrm{~mL}$ de colostro, em frascos estéreis tipo Falcon, os quais foram acondicionados em caixas isotérmicas sem a presença de gelo e encaminhados até ao laboratório de Microbiologia da Universidade Federal de Pelotas, o tempo de transporte foi em torno de até 60 minutos.

O preparo da silagem de colostro seguiu a metodologia descrita por Saalfeld et al. (2013). Para isso, um volume de $237 \mathrm{~mL}$ de colostro foi acondicionado em garrafas de polietileno tereftalato (PET). As garrafas foram completamente preenchidas, fechadas e mantidas em temperatura ambiente por um período de até 365 dias. O volume restante de colostro in natura $(63 \mathrm{~mL})$ foi utilizado para avaliação das propriedades físicas, microbiológicas, imunológicas e determinação dos analitos. A avaliação dessas propriedades no processo de silagem foi realizada em intervalos de sete dias, nos primeiros 21 dias de fermentação anaeróbica do colostro, e a cada 30 dias até o período final de avaliação.

\section{Avaliação física e pH}

Em cada amostra, tanto do colostro in natura $(n=35)$ como do colostro fermentado $(n=45)$, foi realizada a avaliação física (aspecto, coloração, viscosidade, odor e sabor) nos períodos de $7,15,21,30,60,90,120,150,180$ e 365 dias. A viscosidade e coloração foram classificadas de forma subjetiva de 1 a 7 e 1 a 5, respectivamente, segundo descrito por LeBlanc et al. (1986). O pH foi determinado com auxílio de um potenciômetro digital devidamente calibrado. Adicionalmente à avaliação física, incluiu-se odor e sabor, essas características são descritas para o colostro e silagem de bovinos por Saalfeld (2008).

\section{Avaliações microbiológicas}

Alíquotas de $100 \mu \mathrm{L}$ das amostras de colostro in natura e de silagem de colostro foram semeadas em meios de cultura MacConkey, Chapmann, Sabouraud e ágar sangue ovino 5\%. As placas foram incubadas a $37^{\circ} \mathrm{C}$ por 72 horas em aerobiose. Paralelamente um volume de $100 \mu \mathrm{L}$ de colostro in natura e silagem de colostro foram semeados em $9 \mathrm{~mL}$ de caldo Man, 
Rogosa e Sharpe (MRS-Biobras, Brasil) incubado a $37{ }^{\circ} \mathrm{C}$ por 72 horas em microaerofilia e anaerobiose. Posteriormente, alíquotas de $100 \mu \mathrm{L}$ dessa cultura foram repicadas para placas de Petri contendo ágar MRS, sendo incubadas nas mesmas condições citadas acima.

As placas que apresentaram crescimento de colônias bacterianas foram avaliadas pela coloração de Gram e submetidas à identificação bioquímica até o nível de gênero (BARENFANGER, 2003). Para identificação molecular, foi realizada extração total de DNA com pérolas de vidro, em amostras de silagem de colostro de distintos períodos, através do método adaptado de Chagnaud et al. (2001) e amplificação por PCR utilizando os primers que amplificam a região $16 S$.

\section{Determinação de analitos}

Os analitos determinados foram $\mathrm{Ca}, \mathrm{K}, \mathrm{Mg}$ e $\mathrm{Na}$. Foi utilizado um espectrômetro de emissão óptica com plasma induzido por micro-ondas (MIP OES) da Agilent, modelo 4200 (Melbourne, Austrália), equipado com um nebulizador OneNeb e uma câmara de nebulização ciclônica do Laboratório de Metrologia Química da Universidade Federal de Pelotas. A análise foi realizada para o colostro in natura e silagens de colostro até 365 dias. 0 plasma foi mantido com gás nitrogênio, obtido do ar atmosférico através de um gerador de nitrogênio da Agilent, modelo 4107 (Melbourne, Austrália), com vazões de 20 e 1,5 L/min para o gás de plasma e auxiliar, respectivamente.

Para o preparo das amostras foi utilizada uma solubilização alcalina com hidróxido de tetrametilamônio (TMAH), a qual consistiu em pipetar $150 \mu \mathrm{L}$ de amostra de colostro in natura e colostro fermentado diretamente em frascos de polipropileno (PP), sendo, logo em seguida, adicionado $300 \mu \mathrm{L}$ de TMAH 25\% (m/v) (Sigma, Estados Unidos). As amostras foram agitadas e permaneceram overnight a temperatura ambiente. Por fim, foram avolumadas a $2 \mathrm{~mL}$ com água deionizada.

\section{Quantificação de imunoglobulina G}

A detecção de imunoglobulinas no colostro e silagem do colostro foi realizada empregando o método de ELISA (ensaio imunoenzimático) indireto para deteç̧ão de IgG anti Theileria equi (VIANNA et al., 2014). Essa avaliação foi realizada em amostras de colostro de nove éguas 
inoculadas com uma vacina experimental contra T. equi (VIANNA et al., 2014). Seis éguas não vacinadas foram utilizadas como controle.

A avaliação das imunoglobulinas no processo de fermentação da silagem foi realizada em períodos de sete dias, nos primeiros 21 dias de fermentação anaeróbica do colostro, e a cada 30 dias até o período final de avaliação, totalizando 365 dias de fermentação.

\section{Análises estatísticas}

A análise estatística dos dados foi realizada através do software SAS. Para avaliação física foi realizada distribuição de frequência para descrições das características físicas de viscosidade e coloração, sendo os valores expressos em porcentagem, mínimo e máximo.

Para avaliação das diferenças nos valores de pH, determinação dos analitos e dinâmica de IgG em relação ao tempo de fermentação, as variáveis foram submetidas ao teste de Bonferroni, e realizadas pressuposições para análise de variância. A partir dos dados nãonormais, foi realizada transformação logarítmica. As variáveis não-normais ( $\mathrm{K}, \mathrm{Mg}$ e $\mathrm{Na}$ ) foram convertidas em logaritmo base 10 ( $\log 10)$, passando a demonstrar normalidade. Significância foi atribuída ao valor de $p<0,05$.

\section{RESULTADOS E DISCUSSÃO}

O colostro manteve as características avaliadas, sendo de grande importância na alimentação dos potros neonatos, entretanto, o tempo de secreção dessa substância após o parto é muito curto e muitas vezes os potros não conseguem aproveitar totalmente o período de produção desse alimento. Esse fato justifica a necessidade de coletar e estocar o colostro para ser administrado na alimentação diária dos potros neonatos, como um suplemento alimentar. Todavia, é importante preservar os constituintes colostrais para que não se percam as propriedades nutritivas e imunológicas (CANISSO et al., 2013).

\section{Avaliação Física}

O colostro equino in natura $(n=35)$ caracterizou-se por apresentar viscosidade leitosa (11/35), cremo-leitosa (5/35) e cremosa (19/35). Em relação a coloração: amarelo claro (21/35) e amarelo escuro (14/35). A silagem do colostro fermentada foi avaliada fisicamente, nas quais não foram observadas modificações de coloração e viscosidade. Adicionalmente à 
avaliação física das amostras de silagem de colostro, incluiu-se odor e sabor, em que o odor se apresentou semelhante a queijo com sabor ácido e levemente salgado. Os resultados da avaliação de viscosidade e coloração do colostro in natura foram similares aos descritos por Luz et al. (1992), que evidenciaram a relação entre coloração, viscosidade e o teor de imunoglobulinas, sendo um método subjetivo. No presente estudo, pode-se observar que a avaliação física do colostro in natura e silagem do colostro apresentaram boa qualidade, refletindo indiretamente o teor de imunoglobulinas, uma vez que quanto maior a coloração e viscosidade maior a concentração de imunoglobulinas. A manutenção das características físicas da silagem indicou adequada fermentação das amostras avaliadas, demonstrando a viabilidade do método até 365 dias de fermentação.

\section{Avaliação do pH}

A média do pH do colostro in natura foi de 6,17. A partir do sétimo dia de avaliação da silagem de colostro até os 365 dias, os valores de pH diferiram da avaliação inicial, sendo a média 3,83 . Essa redução do $\mathrm{pH}(p<0,005)$ durante os períodos avaliados demonstrou adequado processo fermentativo. Os valores de $\mathrm{pH}$ no colostro in natura e silagens apresentaram valores similares aos descritos por Saalfeld et al. (2013) para silagem de colostro bovino, na qual também se observou redução constante do $\mathrm{pH}$, quanto maior o período de fermentação. A redução do pH observada durante os períodos avaliados demonstrou adequado processo fermentativo, no qual houve conversão de lactose em ácido láctico, influenciando diretamente as características biológicas e impedindo o crescimento e desenvolvimento de micro-organismos patogênicos e de deterioração (SAALFELD et al., 2013). 
Tabela 1 - Valores de pH no colostro in natura e nos distintos períodos de fermentação anaeróbica.

\begin{tabular}{ccc} 
Momento (dias) & $\mathbf{p H}$ \\
\cline { 2 - 3 } & $\mathbf{7}$ & $5,19 \pm 0,07^{\mathrm{a}}$ \\
$\mathbf{1 5}$ & $4,08 \pm 0,17^{\mathrm{b}}$ \\
$\mathbf{2 1}$ & $4,54 \pm 0,11^{\mathrm{c}, \mathrm{d}}$ \\
$\mathbf{3 0}$ & $4,08 \pm 0,08^{\mathrm{d}, \mathrm{e}}$ \\
$\mathbf{6 0}$ & $3,92 \pm 0,05^{\mathrm{e}, \mathrm{f}}$ \\
$\mathbf{9 0}$ & $3,58 \pm 0,13^{\mathrm{f}, \mathrm{g}}$ \\
$\mathbf{1 2 0}$ & $3,82 \pm 0,15^{\mathrm{e}, \mathrm{f}, \mathrm{g}}$ \\
$\mathbf{1 5 0}$ & $3,40 \pm 0,17^{\mathrm{g}}$ \\
$\mathbf{1 8 0}$ & $3,46 \pm 0,10^{\mathrm{f}, \mathrm{g}}$ \\
$\mathbf{3 6 5}$ & $3,46 \pm 0,10^{\mathrm{f}, \mathrm{g}}$ \\
\hline a,b,c,d,ef,g & \\
\hline
\end{tabular}

\section{Analitos}

Os analitos $\mathrm{Ca}$, K e Na não demonstraram alterações durante a fermentação. Os valores de Mg demonstraram interação fraca $(r=0,307)$ com o tempo de armazenamento decorrido, apresentando um discreto aumento na concentração $\left(510,20 \mathrm{mg} \cdot \mathrm{L}^{-1}\right)$ no decorrer dos 365 dias de fermentação, em comparação com o colostro in natura, que apresentou a concentração de 300,20 mg. $\mathrm{L}^{-1}$ (Tabela 1). As determinações de Ca, K e Na mantiveram-se semelhantes aos valores encontrados no colostro in natura até 365 dias de fermentação (Tabela 2), estando as concentrações desses analitos de acordo com os padrões descritos para equinos da raça Árabe (UNANIAN et al., 1994). Porém, não há descrição das concentrações desses analitos na fermentação anaeróbica do colostro equino. A manutenção das concentrações neste estudo, observadas na silagem do colostro, sugerem que o processo de fermentação pode ser utilizado para o armazenamento de colostro equino. Contudo, mais estudos são necessários para sugerir a administração do colostro fermentado para o aleitamento de potros neonatos. A quantificação dos analitos na 
secreção mamária pode ser utilizada para prever o parto em gestações saudáveis, pois ocorre um incremento nas concentrações de Ca e K e um decréscimo nas concentrações de $\mathrm{Na}$ e Cloro (Cl), no período entre o dia anterior e dia do parto (CANISSO et al., 2013). Dessa forma, a avaliação dos analitos nesse período e no colostro in natura pode estimar se houve a formação adequada do colostro. Entretanto, não há descrição da relação dos níveis de eletrólitos no colostro in natura com a qualidade do mesmo.

Tabela 2 - Resultados da média \pm desvio padrão da concentração de $\mathrm{Ca}, \mathrm{Mg}, \mathrm{K}$ e $\mathrm{Na}$ no colostro in natura e nos distintos períodos de fermentação anaeróbica.

\begin{tabular}{|c|c|c|c|c|}
\hline \multicolumn{5}{|c|}{ Concentração (mg.L $\left.{ }^{-1}\right)$} \\
\hline $\begin{array}{l}\text { Momento } \\
\text { (dias) }\end{array}$ & $\mathrm{Ca}$ & Mg & K & $\mathrm{Na}$ \\
\hline Parto & $788,97 \pm 31,66$ & $300,20 \pm 34,42$ & $1365,9 \pm 50,71$ & $344,31 \pm 28,76$ \\
\hline 7 & $785,60 \pm 68,30$ & $373,60 \pm 98,82$ & $1378,8 \pm 77,24$ & $386,60 \pm 84,27$ \\
\hline 15 & $787,00 \pm 68,43$ & $364,20 \pm 96,17$ & $1314,4 \pm 89,30$ & $376,00 \pm 78,08$ \\
\hline 21 & $741,20 \pm 74,37$ & $357,80 \pm 95,79$ & $1237,0 \pm 97,14$ & $324,40 \pm 92,27$ \\
\hline 30 & $651,80 \pm 35,36$ & $340,40 \pm 105,41$ & $1333,0 \pm 96,16$ & $371,00 \pm 61,63$ \\
\hline 60 & $662,40 \pm 41,05$ & $370,00 \pm 116,15$ & $1358,0 \pm 91,45$ & $343,80 \pm 56,95$ \\
\hline 90 & $631,20 \pm 35,99$ & $328,80 \pm 113,34$ & $1244,8 \pm 81,69$ & $336,00 \pm 58,57$ \\
\hline 120 & $726,60 \pm 59,30$ & $484,80 \pm 69,96$ & $1439,2 \pm 226,18$ & $462,00 \pm 85,22$ \\
\hline 150 & $786,40 \pm 43,58$ & $510,00 \pm 71,33$ & $1369,6 \pm 251,58$ & $463,00 \pm 85,08$ \\
\hline 180 & $782,20 \pm 40,24$ & $510,20 \pm 71,78$ & $1314,0 \pm 229,50$ & $443,00 \pm 80,20$ \\
\hline 365 & $782,50 \pm 40,24$ & $510,30 \pm 71,78$ & $1314,0 \pm 209,50$ & $443,00 \pm 80,20$ \\
\hline
\end{tabular}

\section{Quantificação de imunoglobulina G}

A dinâmica da IgG da silagem de colostro se manteve nos períodos avaliados e não demonstrou diferença quando comparada ao colostro in natura. Os níveis dessa imunoglobulina se mantiveram constantes durante os 365 dias de fermentação. Esses resultados demonstraram que a silagem do colostro equino, assim como nos bovinos, constitui-se como um método alternativo de armazenamento para a formação de bancos de 
colostro. Entretanto, é necessária a realização de testes in vivo, a partir do fornecimento para potros neonatos e posterior avaliação de absorção de imunoglobulinas. Segundo SIMON et al. (2012), uma característica da espécie equina é a ausência de imunidade humoral ao nascimento, o que justifica a importância do colostro como método de imunização passiva.

\section{Avaliação microbiológica}

Na cultura microbiológica foi observado crescimento bacteriano em somente $5,7 \%(2 / 35)$ das amostras de colostro in natura e 11,1\% (5/45) das silagens. Baseado na identificação morfológica, bioquímica e molecular, foram classificadas como pertencentes aos gêneros Enterococcus spp. e Lactobacillus spp. (Figura 1). Apesar do pouco crescimento observado, macroscopicamente nos cultivos, a presença bacteriana no colostro in natura e na silagem foi confirmada pela identificação molecular. Similarmente, Saalfeld et al. (2013) ao avaliarem a silagem de colostro bovino, observaram a predominância de bactérias ácido láticas (Lactobacillus e Enterococcus), sugerindo que esses gêneros bacterianos foram os responsáveis pelo processo de fermentação do colostro. Segundo esses autores, bactérias do grupo ácido-lático possuem propriedades probióticas, podendo ser usadas em alimentos tanto para consumo humano quanto animal, as quais acidificam esses alimentos, impedindo o desenvolvimento de bactérias patogênicas. De acordo com Salimei e Fantuz (2012), em equinos a microbiota com maior representatividade no colostro é de bactérias ácido-láticas, porém, a caracterização das espécies não é descrita.

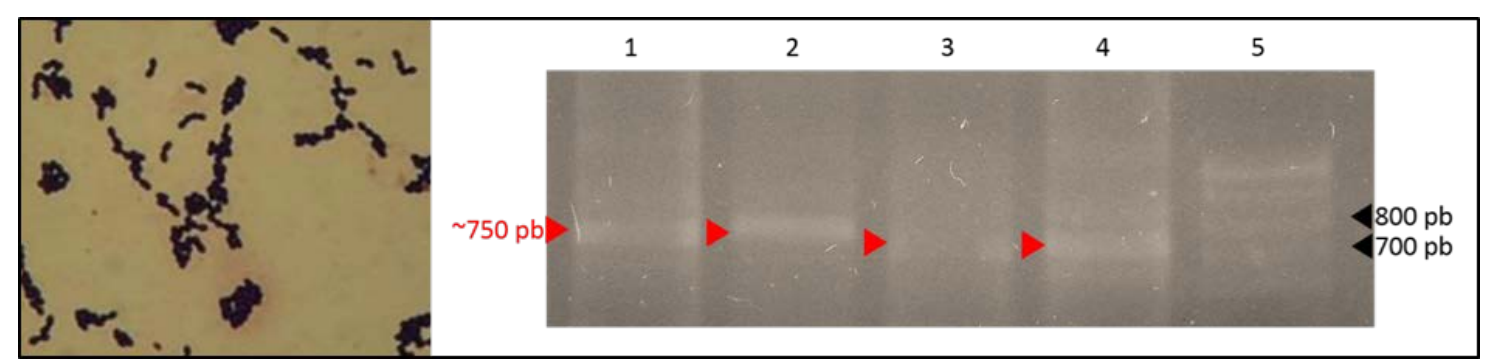

Figura 1 - Enterococcus spp. (coloração de Gram) à esquerda. Gel de agarose 1\% para eletroforese da PCR realizada sobre amostra total de silagem de colostro armazenada por diferentes períodos de fermentação à direita. Linha 1 - colostro "in natura"; Linha 2- 21 dias; Linha 3- 60 dias; Linha 4 - 180 dias; Linha 5 Marcador $100 \mathrm{pb}$ (Ludwigui). 


\section{CONCLUSÃO}

Os resultados deste estudo demonstraram que a fermentação anaeróbica do colostro equino, até 365 dias de fermentação, manteve os constituintes colostrais avaliados semelhantes ao colostro in natura. Os dados permitem inferir que essa técnica demonstrou ser um método econômico, de fácil produção e armazenamento, dispensando equipamentos especiais para sua elaboração. Assim, o colostro anaerobicamente fermentado até 365 dias pode ser um novo método de armazenamento para elaboração de um banco de colostro equino. Entretanto, estudos in vivo são necessários para viabilizar o seu emprego na equideocultura.

\section{ANAEROBIC FERMENTATION OF EQUINE COLOSTRUM}

\section{ABSTRACT}

quine colostrum provides immunoglobulins, nutrients, and growth factors essential to the immunity and survival of the newborn foal. However, in many cases, colostrum intake by the neonate does not occur naturally, and artificial feeding is necessary. Colostrum preservation methods have generated controversial results. The objective of this study was to test the anaerobic fermentation technique of equine colostrum in order to preserve the quality of the product and to evaluate the maintenance of colostrum constituents in vitro. The microbiological and physical properties and the concentration of analytes, $\mathrm{Ca}, \mathrm{K}, \mathrm{Mg}$, and $\mathrm{Na}$ of colostrum in natura and in different periods of anaerobic fermentation were verified. The evaluation of the $\mathrm{pH}$ during the fermentation showed a consistent reduction with the fermentative process. In the different fermentation periods, maintenance of analyte concentrations and immunoglobulin levels was observed. The results of this study show that equine colostrum silage maintains the properties evaluated in vitro.

Keywords: Silage. Immunity. Immunoglobulins. 


\section{FERMENTACIÓN ANAERÓBICA DEL CALOSTRO EQUINO}

\section{RESUMEN}

$\mathrm{E}$ I calostro equino proporciona inmunoglobulinas, nutrientes y factores de crecimiento esenciales para la inmunidad y la supervivencia del potro neonato. Sin embargo, en innumerables casos la ingestión del calostro por el neonato no ocurre de forma natural, siendo necesario la lactancia artificial. Los métodos de preservación del calostro han generado resultados controvertidos. El objetivo de este estudio fue probar la técnica de fermentación anaeróbica del calostro equino a fin de preservar la calidad del producto y evaluar in vitro el mantenimiento de los constituyentes calostrales. Se verificaron las propiedades microbiológicas y físicas y la concentración de analitos, $\mathrm{Ca}, \mathrm{K}, \mathrm{Mg}$, y $\mathrm{Na}$ del calostro in natura y en distintos períodos de fermentación anaeróbica. La evaluación del pH en el transcurso de la fermentación demostró una reducción acorde con el proceso fermentativo. En los distintos períodos de fermentación, se observó el mantenimiento de las concentraciones de los analitos y de los niveles de inmunoglobulinas. Los resultados de este estudio evidencian que el ensilaje del calostro equino mantiene las propiedades evaluadas in vitro.

Palabras clave: Ensilaje. Inmunidad. Inmunoglobulinas.

\section{AGRADECIMENTOS}

Os autores agradecem à Coordenação de Aperfeiçoamento de Pessoal de Nível Superior (Coordenação de Aperfeiçoamento de Pessoal de Nível Superior - CAPES Código de financiamento 001).

\section{REFERÊNCIAS}

ANDRADE, D. A. P.; BORGER, I.; ALVES, L. R. N.; et al. Silagem de colostro na alimentação de ruminantes. Nutritime, v. 9, p. 1816-1830, 2012. Disponível em:

<http://www.nutritime.com.br/arquivos_internos/artigos/artigo\%20165_.pdf>.

BARENFANGER, J. Improving the clinical utility of microbiology data: an update. Clinical Microbiology Newsletter, v. 25, n. 1, p. 1-8, 2003. 
CANISSO, I. F.; BALL, B. A.; TROEDSSON, M. H.; et al. Decreasing pH of mammary gland secretions is associated with parturition and is correlated with electrolyte concentrations in prefoaling mares. Veterinary Record, v. 173, n. 9, p. 218, 2013. doi:

http://dx.doi.org/10.1136/vr.101658

CHAGNAUD, P.; MACHINIS, K.; COUTTE, L. A.; et al. Rapid PRC-based procedure to identify lactic acid bacteria: application to six common Lactobacillus species. Journal of Microcbiological Methods, v. 44, n. 2, p. 139-148, 2001. doi: http://dx.doi.org/10.1016/s0167-7012(00)00244-x

GARDNER, R. B.; NYDAM, D. V.; LUNA, J. A.; et al. Serum opsonization capacity, phagocytosis, and oxidative burst activity in neonatal foals in the intensive care unit. Journal of Veterinary Internal Medicine, v. 21, n. 4, p. 797-805, 2007. doi: https://doi.org/10.1111/j.19391676.2007.tb03024.x

GIGUERE, S; POLKES, A. C. Immunologic disorders in neonatal foals. Veterinary Clinics of North America: Equine Practice, v. 21, n. 2, p. 241-272, 2005. doi: https://doi.org/10.1016/j.cveq.2005.04.004

LEBLANC, M. M.; MCLAURIN, B. I.; BOSWELL, R. Relationship among serum immunoglobulin concentration in foals, colostral specific gravity, and colostral immunoglobulin concentration. Journal of the American Veterinary Medical Association, v. 189, n. 1, p. 5760, 1986. Disponível em: <https://www.ncbi.nlm.nih.gov/pubmed/3733502> .

LUZ, I. N. C.; ALDA, J. L.; SILVA, J. H. S.; et al. A Viscosidade, A Coloração e a Gravidade Específica do Colostro no Prognóstico da Concentração de Imunoglobulina Sérica de Potros Recém-Nascidos. Ciência Rural, v. 22, n. 3, p. 299-305, 1992. doi: http://dx.doi.org/10.1590/\$0103-84781992000300009

PEREIRA, C. C.; VITOLA, H. R. S.; SOUZA, A. L.; et al. Decomposition method in semi-closed system with cold finger for evaluation of $\mathrm{Ca}, \mathrm{K}, \mathrm{Mg}, \mathrm{Zn}$ and $\mathrm{Fe}$ in colostrum silage by $\mathrm{F}$ AAS and F AES. Microchemical Journal, v. 129, p. 293-296, 2016. doi:

https://doi.org/10.1016/j.microc.2016.07.012

SAALFELD, M. H. Uso da silagem de colostro como substituto do leite na alimentação de terneiras leiteiras. A Hora veterinária, v. 162, p. 59-62, 2008.

SAALFELD, H. M.; PEREIRA, D. I. B.; SILVEIRA, K. R. K.; et al. Anaerobically fermented colostrum: an alternative for feeding calves. Ciência Rural, v. 43, n. 9, p. 1636-1641, 2013. doi: http://dx.doi.org/10.1590/\$0103-84782013000900016

SALIMEI, E.; FANTUZ, F. Equid milk for human consumption. International Dairy Journal, v. 24, n. 2, p. 130-142, 2012. doi: https://doi.org/10.1016/j.idairyj.2011.11.008 
SIMON, B. B. Z.; RONCATI, N. V.; HOGE, A. Y. A.; et al. Perfil Celular do Colostro de Éguas: Estudo Preliminar. Revista de Educação Continuada em Medicina Veterinária e Zootecnia do CRMV-SP, v. 10, n. 2-3, p. 32-36, 2012. Disponível em: <https://www.bvsvet.org.br/vetindex/periodicos/revista-de-educacao-continuada-em-medicina-veterin/10(2012)-2-3/perfil-celular-do-colostro-de-eguas-estudo-preliminar/> .

UNANIAN, M. M.; SILVA, A. E. D. F.; PEREIRA, A. C. Colostro de égua no aleitamento artificial. (EMBRAPA-CPPSE). Circular Técnica São Carlos: EMBRAPA - CPPSE, v. 8, p. 21, 1994.

VIANNA, A. M.; GONÇALES, R. A.; LARA, A. P. S. S.; et al. Expressão heteróloga da EMA-2 (equi merozoite antigen) de Theileria equi em Pichia pastoris com potencial utilização em imunobiológicos. Ciência Rural, v. 44, n. 10, p. 1830-1836, 2014. doi:

http://dx.doi.org/10.1590/0103-8478cr20131003

Autor para correspondência: Carolina Litchina Brasil. Avenida Pinheiro Machado, n. 506, apto. 301 I, Fragata, Pelotas/RS, CEP: 96.040-500. carolinalitchinabrasil@hotmail.com 